\title{
A Comparison of the Effectiveness of Social Skills Training and Anger Management on Adjustment of Unsupervised Girl Adolescents
}

\author{
Tayebeh Mokhber, Abbas Masjedi*, Maryam Bakhtiari \\ Faculty of Medicine, Shahid Beheshti University of Medical Sciences, Tehran, Iran \\ Email: ^doctormasjedi@yahoo.com
}

How to cite this paper: Mokhber, T., Masjedi, A. and Bakhtiari, M. (2016) A Comparison of the Effectiveness of Social Skills Training and Anger Management on Adjustment of Unsupervised Girl Adolescents. Journal of Behavioral and Brain Science, 6, 530-538.

http://dx.doi.org/10.4236/jbbs.2016.612047

Received: August 31, 2016

Accepted: November 27, 2016

Published: November 30, 2016

Copyright $\odot 2016$ by authors and Scientific Research Publishing Inc. This work is licensed under the Creative Commons Attribution International License (CC BY 4.0). http://creativecommons.org/licenses/by/4.0/

\begin{abstract}
This study aimed at a comparison of the effectiveness of social skills training and anger management on adjustment of unsupervised girl adolescents between 15 - 18 years old in Tehran. This research was an experimental one with plan of pre-test and post-test control groups. The statistical universe of this research was consisted of all unsupervised girl adolescents between 15 - 18 years old in Tehran. The subject was 35 unsupervised girl adolescents who are assigned to two groups: experimental and control group. Data were collected by using the Adjustment Inventory for School Students (AISS). Multivariate analysis of covariance showed that the social skills training and anger management significantly increased social, emotional and educational adjustment on the experimental group $(\mathrm{P}<0.05)$. But Tukey's follow-up test showed that there wasn't significant difference between effectiveness of training anger control on compatibility and effectiveness of training social skills on individuals' total compatibility. Findings showed that both trainings could be used in the same extent in order to enhance compatibility level.
\end{abstract}

\section{Keywords}

Social Skills Training, Anger Management Training, Adjustment, Unsupervised

\section{Introduction}

Adolescence is a time which links kids into adulthood. It is associated with physical, mental, emotional, cognitive and behavioral changes in this era of conflicts and discrepancies [1]. Adolescents are at this critical time, suffering from intense emotions and feelings of uncertainty, conflict and aggression, while the society wants them to be independent, to well manage the change to the adulthood, and to adapt to and prepare for job findings [2]. Sudden and massive changes in all aspects of adolescent life lead to a 
critical step that naturally creates problems and conflicts [3]. Teens feel low due to little experience and skills to adapt more readily to tackle anti-social behavior such as stealing, running away from home and school and substance abuse [4]. Mohammadi prevalence of mental health problems among children and adolescents in different countries from $3 \%$ to $24 \%$ has declared [5] According to theoretical foundations, more than a fifth of children suffer from at least one mental health problem [6].

On the other hand, communication with their environment on the stress of this transition is effective and family is one of the most dynamic areas where teenager will be influenced and affected. Experts believe that warm and a friendly family environment where parents and other family members have good and friendly relations usually cultivate children's healthy and positive personality. Moreover, the children who are the lack of a family or living in a divorced or single parent family may have distortions in their personality [7].

Although most parents love their children and they are trying to cultivate them, some parents cannot take care of their children and some others think that the quality of care is not necessary. This is especially true in the case of children who lose their parents and orphans reasons are not visible. Unfortunately in today's society with rising divorce rate, drug addiction, poverty and the consequences of industrialization of societies, the phenomenon of irresponsibility of parents and the orphans are increasing significantly. There is a high prevalence of signs of stress in children and adolescents orphans who are neglected by their irresponsible parents or the society [8].

One of the common problems of adolescents is the inconsistency with the surrounding environment. Compatibility is the ability of individuals to adapt to unfavorable conditions and environmental stress with healthy and flexible deployment methods, to help for individuals' personal understanding on others personality, to be courageous, determined, and able to restore the balance and meaning in life [9]. The factors shaping adaptability include social skills, anger management and deployment associated with family members and peers, kids.

According to researches carried out, lack of anger control may cause a lot of problems in job, interpersonal relationship and overall quality of life [10], and may lead to drug and alcohol abuse, smoking, low compatibility in school, academic failure, depression, delinquency and other disorders [11]. The study results in this field indicated the effectiveness of anger management training on reducing aggression [12] increased compatibility and social skills [13], and increased insight [14]. The meta-analysis also show- ed in 2013 that this type of education was considered as first-line treatment for disruptive behavior and the effect size is 1.17 according to the report [15].

One the other hand, social skills are set of capabilities that help starting and maintaining positive social relationship, friendship and intimacy with peers. They help you to make satisfactory adjustments, to adapt to your permitted social and environment conditions, to connect with others; which lead to positive and avoid negative responses. [16].

The study results in this field indicated the effectiveness of social skills training on, 
social adjustment, emotion, behave, and self-concept [17] [18], improved the quality of life and mental health and increased empathy, self-esteem and consistency [19] [20]. A systematic review and meta-analysis results also showed that, in a series of studies on adolescents who prone to have emotional and behavioral problems, social skills training in two-thirds of the teens improved the social competence [21].

According to what was mentioned, controlling anger and using appropriate social skills in communicating with family members and peers to improve compatibility aspects including emotional, social and educational influence are important, because failure in this area can lead to damaing, because failure in this area can be damaging consequences, including a variety of anomalies, insecurity, personal problems, emotional and behavioral disorders and delinquency to be followed. Finally, this study highlights the importance of the course and consequences of conflict. It attempts to answer this fundamental question on the difference between the effectiveness of two methods on anger control training and social skills training on adaptation in unsupervised girls.

\section{Material and Methods}

The research method and experiment contain pretest-posttest control group. Our plan is the pre-test and post-test of three groups for the two experimental groups and one control group [10].

This research consists of girls between 15 - 18 years in Tehran. The sample consists of 35 subjects (12 subjects in groups of anger, 11 subjects in group of social skills training and 12 subjects in the control group).

The inclusion criteria of the study are: patients who age from 15 to 18 years old; lack of sufficient performance at least one parent; have psychotic spectrum disorders, do not have autistic spectrum disorders, chronic physical illness, and neurological disease. The exclusion criteria are: patients suffer from psychiatric and psychological intervention at the same time, who are in absence of the study for more than three days and who do not want to participate in the training group sessions.

The following tool was used to collect data: Adjustment Inventory for School Students (AISS). The questionnaire was designed to fit for high school students by buses from 15 to 18 years old students in three areas: emotional, social and educational aspects in terms of compatibility. How to respond to this questionnaire is self-evaluated with answers of "yes" or "no". When answering "Yes", a score is considered; and when answering "No", it means zero. This 60-item questionnaire was then translated into Persian based on standardization, validity and reliability, and removed inappropriate ones through factor analysis. The 30-item version was prepared according to Iranian society. Content validity of the questionnaire was confirmed by professors and experts who confirmed its validity by standardization. The reliability of the questionnaire is 0.95 , Cronbach's alpha for overall consistency is 0.76 ; for emotional adjustment is 0.72 ; and for social adjustment is 0.71 and academic adjustment is 0.73 as been reported [22].

After the implementation of the pre-test questionnaire, the data of the first experimental group and the second group, anger control training, social skills training are 
shown in Table 1 (each of 12 sessions 60 -minute). It should be noted that the control group received no intervention. After the training, as post-test questionnaires and six weeks later in order to track the results were implemented.

\section{Results}

According to the results (Table 2), the highest percentage of participants is in the age group of 15 year (40 percent) and the lowest percentage of respondents (14.3 percent) in the age group of 18 and 17 years old. Father's education: $2.85 \%$ of the respondents were illiterate, $11.42 \%$ were of primary school education, $25.71 \%$ were of third grade

Table 1. Social skills training and anger management groups.

Social skills training
First session: Meet the members of the group,
reviewing the goals of the group, rules Group
as well as the conceptual framework and the
importance of social skills.

Second Session: Practice your presentation and give feedback, training on body language and nonverbal communication.

Third session: review homework, introduced a variety of active and passive listening, learning techniques listen.

Fourth session: training techniques and venturing boldly member of the group, do exercises in the correct and transparent express feelings, wants, desires, thoughts and opinions without desecrating and violating the rights of others.

Fifth Session: Teaching methods and express their opinion and feedback.

Sixth Session: Review concepts learned, review homework.

Seventh and eighth sessions: Education discusses ways to criticize criticism and a variety of reactions and strategies for how to deal with criticism.

Ninth and tenth sessions: the necessity of learning and teaching techniques say no to it, teaching practical techniques to deal with stressful situations.

Eleventh Session: Review concepts learned, encouraged in order creating balance in the use of cognitive behavioral strategies, immediate and proactive.

Twelfth session: review of social skills programs by group members, summary and post-test performance.
Anger Control Training

First session: Meet the members of the group, reviewing the goals of the group, rules group as well as conceptual and logical framework anger management therapy

Second Session: Learn how to analyze the course of his anger, identify events and marks the beginning of anger, listing specific events trigger anger in people and finding different events and interpretation of events.

Third session: training cognitive behavioral strategies control anger immediate and preventive training and relaxation through breathing interruptions strategies.

Fourth Session: Training courses aggression that included a three-stage start-export and post-export is also progressive muscle relaxation session ended with the training and use of technology.

Fifth Session: A-B-C-D model of education as cognitive restructuring and fans stop thinking model.

Sixth Session: Review concepts learned, review homework

Seventh and eighth sessions: skills training assertiveness, aggression, passivity and conflict resolution model

Ninth and tenth sessions: Effect of past learning on current behaviors;

Eleventh Session: Review concepts learned, encouraged in order creating balance in the use of cognitive behavioral strategies, immediate and proactive.

Twelfth Session: Browse by members of anger management programs; summary and post-test performance 
high school education, $22.85 \%$ were diplomas and $8.57 \%$ were associate's degree. $28.57 \%$ did not specify their father's education. As for maternal education, $5.71 \%$ of the participants were illiterate, $22.85 \%$ were of elementary grade, $14.3 \%$ were of third grade high school education, $31.42 \%$ were diplomat, and $28.57 \%$ did not specify their maternal education.

Table 3 shows the mean and standard deviation of compatibility unsupervised adolescent girls in three groups on the basis of pre-test and post-test show. As can be seen the mean difference between control and experimental groups on posttest dimensions of compatibility is evident, so that an average size of compatibility tests in groups at post-test than pre-test.

Table 2. Frequency distribution and percentage of subjects based on age and educational status.

\begin{tabular}{cccc}
\hline Percent & Frequency & \multicolumn{2}{c}{ Variable } \\
\hline 40 & 14 & 15 & Age status \\
31.42 & 11 & 17 & \\
14.3 & 5 & 18 & Father Education \\
14.3 & 5 & Illiterate & \\
2.85 & 1 & Primary & \\
11.42 & 4 & Third grade guidance & \\
25.71 & 9 & Diploma & \\
22.85 & 8 & Associate Degree & \\
8.57 & 3 & Unresponsive & \\
28.57 & 10 & Illiterate & \\
5.71 & 2 & Primary & \\
22.85 & 7 & Third grade guidance & \\
14.3 & 5 & Diploma & \\
31.42 & 11 & Unresponsive & \\
28.57 & 10 & & \\
& & & \\
& & &
\end{tabular}

Table 3. Means and standard deviation (SD) of social, emotional and educational adjustment in the control and experiment group.

\begin{tabular}{ccccc}
\hline \multirow{2}{*}{ Variables } & Stages & Control Group & $\begin{array}{c}\text { Anger Management } \\
\text { Training }\end{array}$ & $\begin{array}{c}\text { Social Skills } \\
\text { Training }\end{array}$ \\
\cline { 3 - 5 } & & $\mathrm{M} \pm \mathrm{SD}$ & $\mathrm{M} \pm \mathrm{SD}$ & $\mathrm{M} \pm \mathrm{SD}$ \\
\hline $\begin{array}{c}\text { Social } \\
\text { Adjustment }\end{array}$ & Pre-test & $7.83 \pm 2.21$ & $6.08 \pm 1.08$ & $6.36 \pm 2.69$ \\
& Post-test & $7.41 \pm 1.83$ & $10.50 \pm 1.09$ & $10.00 \pm 1.34$ \\
Emotional & Pre-test & $5.00 \pm 3.10$ & $5.92 \pm 1.83$ & $6.45 \pm 3.59$ \\
Adjustment & Post-test & $6.75 \pm 2.63$ & $11.50 \pm 1.83$ & $11.64 \pm 2.25$ \\
& Pre-test & $8.17 \pm 1.80$ & $7.92 \pm 1.73$ & $8.00 \pm 2.86$ \\
$\begin{array}{c}\text { Educational } \\
\text { Adjustment }\end{array}$ & Post-test & $8.00 \pm 1.70$ & $10.25 \pm 2.18$ & $9.91 \pm 1.51$ \\
\hline
\end{tabular}


Before using parametric tests, MANCOVA was implemented, in accordance with Table 4 and Table 5 of the box. Levene tests were used as well. Based on the test box, there was no significant for any of the variables. The condition of homogeneity of variance-matrix/covariance is properly respected $(\mathrm{BOX}=17.827, \mathrm{~F}=1.280, \mathrm{P}=0.223$ ). According to Levene test for posttest and non-significant for all variables, the condition of equality between group variances was not met.

Wilks Lambda results showed that the studied groups at posttest at least one of the dependent variables have significant differences (Wilks' Lambda $=0.001>\mathrm{P}, 6.53=\mathrm{F}$, $0.336)$.

Also according to the Chi Eta, it was found that the difference between the two groups was significant with respect to the dependent variables. The difference in posttest and the Wilks Lambda test is $42 \%$ (Partial Eta Squared $=0.420$ ), i.e. $42 \%$ of the variance of the difference between the three groups. The effect is dependent variables.

As Table 6 shows that the results with a control effect of pre-test, post-test in terms of the mean scores of social adjustment $(\mathrm{F}=22.05)$, emotional adjustment $(\mathrm{F}=11.62)$ and training adaptations $(\mathrm{F}=3.98)$ between groups have a significant difference $(\mathrm{P}<$ 0.05).

Finally, the results, in this post hoc test showed that the mean scores of social adjustment, excitement and training in both experimental groups and social skills training, anger is significantly higher than the control group $(\mathrm{P}<0.05)$. However, a significant difference between the mean scores of social adjustment, excitement and training those in the two groups was observed.

Table 4. Box's test of equality of covariance matrices.

\begin{tabular}{cccccc}
\hline Box's M & $\mathrm{F}$ & $\mathrm{df}_{1}$ & $\mathrm{df}_{2}$ & Sig & \\
\hline 17.827 & 1.280 & & 12 & 4.874 & 0.223 \\
\hline
\end{tabular}

Table 5. Levene's test of equality of error variances.

\begin{tabular}{ccccc}
\hline Variables & $\mathrm{F}$ & $\mathrm{df}_{1}$ & $\mathrm{df}_{2}$ & Sig \\
\hline Social Adjustment & 0.970 & 2 & 32 & 0.390 \\
Emotional Adjustment & 0.155 & 2 & 32 & 0.857 \\
Educational Adjustment & 0.179 & 2 & 32 & 0.837 \\
\hline
\end{tabular}

Table 6. Results of multivariate covariance analysis of mean scores of social, emotional and educational adjustment at post-test in both control and experimental groups.

\begin{tabular}{ccccccc}
\hline & Dependent Variable & SS & df & MS & F & Sig \\
\hline \multirow{3}{*}{ Group } & Social Adjustment & 79.92 & 2 & 39.96 & 22.05 & 0.001 \\
& Emotional Adjustment & 116.04 & 2 & 58.02 & 11.62 & 0.001 \\
& Educational Adjustment & 28.78 & 2 & 14.39 & 3.98 & 0.030 \\
\hline
\end{tabular}




\section{Discussion}

The aim of this study was to compare the effectiveness of two methods of anger management and social skills training for the compatibility of unsupervised girls. According to the study, both group's anger control training and social skills to increase compatibility affect unsupervised girls. In other words, the average grades adaptability, in experimental groups compared to control group had increased substantially. The results of this study showing the efficacy of cognitive behavioral techniques and specially trained anger management and social skills on compatibility are consonant with other studies [12] [13] [14] [15] [17] [18] [19] [20].

In explaining the effectiveness of anger control training, the trainees receive cognitive-behavioral approach to anger management. Cognitive restructuring techniques are used to better control anger outward expression of their business.

The ability to look at the dynamics of the the events, they have a significant impact on interpersonal interactions, thereby leading to increase consistency and reduce conflict. In this way and in line with these results, Pellegrino's (2012) study showed that training based on cognitive-behavioral therapy could reduce the anger and problems arising from lack of control in high school and gain insight and knowledge of it [12].

Another study in 2013 showed that this type of education was considered as first-line treatment for disruptive behavior and effect size 1.17 for that report [15]. Dortaj and Asadzadeh, two among those 34 students aged 12 to 15 years old who participated this study, reduced aggression and anger management after training [13].

On the other hand, it can be said in explanation of the effectiveness of social skills training, possible reasons for the increase in the acquisition and application of compatibility are training of social skills of the subjects. Teens that have real social skills to learn, practice and apply their competence certainly can be successful in the peer group and friends, and have positive engagement in relations with their peers and show the range of acceptable behaviors.

The effectiveness can be successful to have the experience of interacting with peers in the department. However, previous studies have also certified that learning and applying communication skills with others, and understanding of the behaviors would reduce interpersonal conflicts. For this reason, the incompatibility of a person cuts and increases his level of consistency. In this regard, it is in accordance with the results that social skills training on empathy, self-esteem and compatibility affects young people and improve these dates [20].

Cook et al. in a series of studies with a meta-analysis concluded that social skills training in two-thirds of adolescents were prone to behavioral and emotional problems to improve their social competence [21].

The post hoc test also showed three types of intervention (education, anger management and social skills) and no significant difference was seen in any of compatibility. In other words, although each of training groups of anger management and social skills could have a significant impact, but there was no significant difference between these two types of intervention for unsupervised compatibility girls. 
This result may suggest that the band and group interaction, more than any other factor, has an effect on improving compatibility for unsupervised adolescents affected. That is, it seems that there are kinds of intimate interactions in these two groups and thus members of the group experience emotional discharges and the other members also hear the common problems, which largely increases their ability to cope with individual circumstances and the compatibility of the participants.

The study of adolescent unsupervised girls why the results generalize is still limited. The time limit for providing education and the small sample size for this study are other restrictions of the subjects.

The lack of follow-up study because of its difficulty of access participants was another limitation of this study.

It is recommended that compared with the other groups, the brighter spots in this context are unclear.

\section{References}

[1] Balilashak, N., Safavi, M. and Mahmoudi, M. (2010) Comparative Assessment of Mental Health of Gifted and Average Students of Junior High School. Procedia-Social and Behavioral Sciences, 5, 2027-2033. https://doi.org/10.1016/j.sbspro.2010.07.408

[2] Bernard, H.W. (1991) Adolescent Development. International Text Book Company.

[3] Noori Ghasem Abadi, R. (1998) Life Skills Training Program.

[4] Nightingale, E. (2002) Adolescent Risk \& Vulnerability: Overview. Journal of Adolescent Health, 31, 3-9. https://doi.org/10.1016/S1054-139X(02)00413-5

[5] Mohammadi, M., Bagheriyazdi, S., et al. (2003) Epidemiological Study of Psychiatric Disorders in Tehran Province. Iranian Journal of Psychiatry and Clinical Psychology, 9, 4-14.

[6] Cuner-Kucukkaya, P. and Işık, I. (2010) Predictors of Psychiatric Symptom Scores in a Sample of Turkish High School Students. Nursing \& Health Sciences, 12, 429-436. https://doi.org/10.1111/j.1442-2018.2010.00553.x

[7] Keisha, L., Kenneth T., Deneia, T., Patton, G., Carrie, B. and Clarissa, R.-B. (2009) Influence of Multiple Attachments on Well-Being: A Model for African Americans Attending Historically Black Colleges and Universities. Journal of Diversity in Higher Education, 2, 35-45.

[8] Hoksbergen, R.A.C., ter Laak, J., van Dijkum, C., Rijk, S. and Rijk, K. (2003) Post Traumatic Stress Disorder in Adopted Children. American Journal of Ortho Psychiatry, 73, 255-265. https://doi.org/10.1037/0002-9432.73.3.255

[9] Tusaie, K., Puskar, K. and Sereika, S.M. (2007) A Predictive and Moderating Model of Psychosocial Resilience in Adolescents. Journal of Nursing Scholarship, 39, 54-60. https://doi.org/10.1111/j.1547-5069.2007.00143.x

[10] American Psychological Association (2004) Controlling Anger before It Controls You.

[11] Disqiuseppe, R.C. (2003) Aggression in Adolescents. Journal of Clinical Psychology, 10, 254-260.

[12] Maleki, S., Rahgooi, A. and Rahgozar, M. (2011) The Effect of Anger Management Training in Groups on Aggression of 12 - 15 Years Old Male Students. Iran Journal of Nursing, 24, 26-35.

[13] Fariborz, D., Asad Elah, M. and Hasan, A. (2010) The Effect of Anger Management Training on Aggression and Social Adjustment of 12 - 15 Years Old Male Students. Journal of 
Applied Psychology, 3, 62-72.

[14] Pellegrino, B. (2012) Evaluating the Mindfulness-Based and Cognitive-Behavior Therapy for Anger Management Program. PhD Dissertation, Philadelphia College of Osteopathic Medicine, Philadelphia.

[15] Comer, J.S., Chow, C., Chan, P.T., Cooper-Vince, C. and Wilson, L.A.S. (2013) Psychosocial Treatment Efficacy for Disruptive Behavior Problems in Very Young Children: A Meta-Analytic Examination. Journal of the American Academy of Child and Adolescent Psychiatry, 52, 26-36. https://doi.org/10.1016/j.jaac.2012.10.001

[16] Gresham, T.S., Watson, T.S. and Skinner, C.H. (2001) Functional Behavioral Assessment: Principles, Procedures and Future Directions. School Psychology Review, 30, 150-172.

[17] Harrell, A., Mercer, S. and DeRosier, M. (2009) Improving the Social-Behavioral Adjustment ofAdolescents: The Effectiveness of a Social Skills Group Intervention. Journal of Child and Family Studies, 18, 378-387. https://doi.org/10.1007/s10826-008-9241-y

[18] Hosseini, R. (2013) The Study of Interpersonal Skills Training to Increase Social Adjustment in Adolescents. 6 th International Congress on Child and Adolescent Psychiatry.

[19] Taussig, H.N. and Culhane, S.E. (2010) Impact of a Mentoring and Skills Group Program on Mental Health Outcomes for Maltreated Children in Foster Care. Archives of Pediatrics \& Adolescent Medicine, 164, 739-746. https://doi.org/10.1001/archpediatrics.2010.124

[20] Yadav, P. and Iqbal, N. (2009) Impact of Life Skill Training on Self-Esteem, Adjustment and Empathy among Adolescents. Journal of the Indian Academy of Applied Psychology, $35,61-70$.

[21] Cook, C.R., Gresham, F.M., Kern, L., Barreras, R.B., Thornton, S. and Crews, S.D. (2008) Social Skills Training for Secondary Students with Emotional and/or Behavioral Disorders: A Review and Analysis of the Meta-Analytic Literature. Journal of Emotional and Behavioral Disorders, 16, 131-144. https://doi.org/10.1177/1063426608314541

[22] TalayianZirak, Z. (2013) Normalization of Adolescent Adaption Scale.

Submit or recommend next manuscript to SCIRP and we will provide best service for you:

Accepting pre-submission inquiries through Email, Facebook, LinkedIn, Twitter, etc.

A wide selection of journals (inclusive of 9 subjects, more than 200 journals)

Providing 24-hour high-quality service

User-friendly online submission system

Fair and swift peer-review system

Efficient typesetting and proofreading procedure

Display of the result of downloads and visits, as well as the number of cited articles

Maximum dissemination of your research work

Submit your manuscript at: http://papersubmission.scirp.org/

Or contact jbbs@scirp.org 